\title{
Understanding and responding to danger from climate change: the role of key risks in the IPCC AR5
}

\author{
Katharine J. Mach $^{1}$ • Michael D. Mastrandrea ${ }^{1}$. \\ T. Eren Bilir ${ }^{1}$ - Christopher B. Field ${ }^{1}$
}

Received: 17 July 2015 / Accepted: 27 February 2016 / Published online: 11 March 2016

(C) The Author(s) 2016. This article is published with open access at Springerlink.com

\begin{abstract}
The IPCC's Fifth Assessment Report (AR5) identifies key risks in a changing climate to inform judgments about danger from climate change and to empower responses. In this article, we introduce the innovations and implications of its approach, which extends analysis across sectors and regions, and consider relevance for future research and assessment. Across key risks in the AR5, we analyze the changing risk levels and potential for risk reduction over the next few decades, an era with some further committed warming, and in the second half of the 21 st century and beyond, a longer-term era of climate options determined by the ambition of global mitigation. The key risk assessment underpins the IPCC's conclusion that increasing magnitudes of warming increase the likelihood of severe, pervasive, and irreversible impacts. Here, we emphasize central challenges in understanding and communicating risks. These features include the importance of complex interactions in shaping risks, the need for rigorous expert judgment in evaluating risks, and the centrality of values, perceptions, and goals in determining both risks and responses.
\end{abstract}

Anthropogenic interference with the climate system is occurring (IPCC 2013). The impacts of climate changes that have already occurred are widespread and consequential, and with continued high emissions or even with ambitious mitigation, large and uncertain consequences will play out over long timeframes (IPCC 2014c). These conclusions are deeply rooted in scientific understanding assessed comprehensively by the IPCC. They also propel us to an assessment frontier: how can we inform solutions through innovative conceptualizations of the climate challenge in assessment?

In this article, we provide an overview of one response to this question: the key risk approach applied across the Working Group II contribution to the IPCC's AR5 (WGII AR5). We discuss why the key risk approach was developed, how it works, and what it implies across sectors and regions, informing both research and assessment.

Katharine J. Mach

kmach@carnegiescience.edu

1 Department of Global Ecology, Carnegie Institution for Science, Stanford, CA, USA 


\section{A challenge in managing risks}

The integrative WGII AR5 key risk assessment is grounded in a view of climate change as a challenge in understanding, reducing, and managing risks (IPCC 2014c). In the AR5, risk is defined as "the potential for consequences where something of value is at stake and where the outcome is uncertain," recognizing that risks will be characterized and perceived differently by people with diverse values (IPCC 2014b). Risk emerges from the interaction of hazards (the physical trigger from the climate system), exposure (the people, ecosystems, and assets at stake), and vulnerability (their susceptibility to harm). It can be represented as the probability of hazards occurring multiplied by the consequences that would result.

The focus on risk is underpinned by salient features of climate change impacts. Most fundamentally, the likelihoods of diverse impacts are shifting through time (e.g., Herring et al. 2014). Uncertainties will persist around the occurrence of specific impacts and the effectiveness of responses. And the relative importance of consequences will remain contested (Knutti and Rogelj 2015; Tschakert 2015). Climate change responses therefore involve making decisions under uncertainty in a changing world, with judgments informed by both science and broader values and goals.

A focus on risk can build bridges from problem to solution in the climate challenge. First, risk encompasses the importance of interactions. The impacts of climate change do not simply result from physical climatic hazards. They emerge from complex interactions among hazards, exposure, and vulnerability - interactions among climate and societies - through space and time (Oppenheimer et al. 2014). Second, risk links present and future experiences. Connecting existing climatic consequences to the changing probabilities of such outcomes under various climate and socioeconomic futures can make potential responses tangible. Third, risk provides a vocabulary and an analytical framework for evaluating the widest possible range of future impacts, including extremes and other low-probability events with severe consequences (e.g., Kunreuther et al. 2013). And finally, risk connects the climate challenge to available tools already used to manage risks across contexts and causes, from security and insurance to business and law (e.g., DHS 2011; Lempert et al. 2003).

\section{Key risks from climate change}

A cohesive global and regional risk assessment, based on available quantitative and qualitative scientific evidence and expert judgment, is a core element of the WGII AR5. The risk assessment establishes a scientific foundation for many decision-making contexts, spanning from international climate negotiations through to private and public efforts at regional, national, and local levels. As part of this assessment across sectors and regions, the report identifies key risks relevant to "dangerous anthropogenic interference with the climate system," a focus central to the ultimate objective of the United Nations Framework Convention on Climate Change. While myriad risks will critically influence specific decisions in a changing climate, including important local decisions, the key risk approach provides an orientation to potential consequences deserving the fullest measure of society's attention.

In the AR5, key risks are defined as "potentially severe adverse consequences for humans and social-ecological systems resulting from the interaction of climate-related hazards with vulnerabilities of societies and systems exposed" (IPCC 2014a). Across the report, WGII AR5 authors identified key risks based on expert judgment using the following specific criteria: 
large magnitude or high probability of impacts, importance of the affected systems, timing or irreversibility of impacts, persistent vulnerability or exposure contributing to risks, or limited potential to reduce risks through adaptation or mitigation. The key risk approach builds from prior IPCC assessment methods informing judgments about danger from climate change (IPCC 2007; Schneider et al. 2007; Smith et al. 2001; Smith et al. 2009).

While key risk identification is inevitably rooted in the collective expert judgment of any author team, informed by the IPCC review process, several aspects of the WGII AR5 assessment advanced cohesiveness and sharpened awareness of the ways different approaches influence risk assessment. First, a synthesis chapter identifies key risks spanning across individual sectors and regions (Oppenheimer et al. 2014). These global-scale key risks encompass risk of severe ill-health and disrupted livelihoods from extreme heat and flooding, of food and water insecurity, and of ecosystem and biodiversity loss, as well as systemic risks from extreme events. Second, extending from past reports, five overarching reasons for concern further aggregate the key risk assessment to illustrate growing risk for societies and ecosystems across increasing temperature levels (IPCC 2014c; Oppenheimer et al. 2014). The five reasons for concern unfold the reality that no single metric can encompass all aspects of climate change risk; perspectives on what is at stake in a changing climate depend, for example, on the relative importance ascribed to the present versus the future, to impacts that are fully versus inadequately captured in monetary terms, to consequences for the rich versus the poor, to isolated versus pervasive impacts, and to average versus extreme outcomes. The themes and dimensions of the global-scale key risks and reasons for concern create important entry points for understanding the report's many sectoral and regional key risks.

A major innovation in the WGII AR5 key risk assessment is its application throughout the report at the sectoral and regional level. This application, extending prior global approaches to a finer grain, had to grapple with limitations in available evidence, challenges in achieving consistency, and particularities shaping hazards, exposure, and vulnerability across contexts. Here we evaluate in particular the approach intended to facilitate a consistent evaluation and actionable summary of key risks in each chapter. The approach was developed iteratively in the report's drafting, based on assessment experiences of WGII AR5 author teams and abundant reviewer input during IPCC expert and government review rounds.

\section{High-traction key risk assessment}

The WGII AR5 assessment framework for summarizing key risks from climate change and the potential for risk reduction through adaptation and mitigation consists of several components (Figs. 1 and 2). In total, 142 key risks were evaluated and communicated in the WGII AR5. Visual summaries were presented in 7 sectoral and 9 regional chapters, with 26 regional key risks selected for the WGII Summary for Policymakers (Fig. 2) and 14 sectoral key risks additionally featured in the WGII Technical Summary (Fig. 1) as well as the AR5 Synthesis Report. Below we introduce framework features designed to enable accessible communication of associated expert judgments across the range of research methods and results.

The description of each key risk, along with adaptation challenges and prospects, results from WGII AR5 authors' expert opinion applied to the specific key risk criteria in their sectoral or regional assessment of the literature per the IPCC drafting and review process. The descriptions highlight determinants of risk (vulnerability, exposure, and hazards) and unique features of the risks, including interacting stressors. As part of the multi-criteria process of 


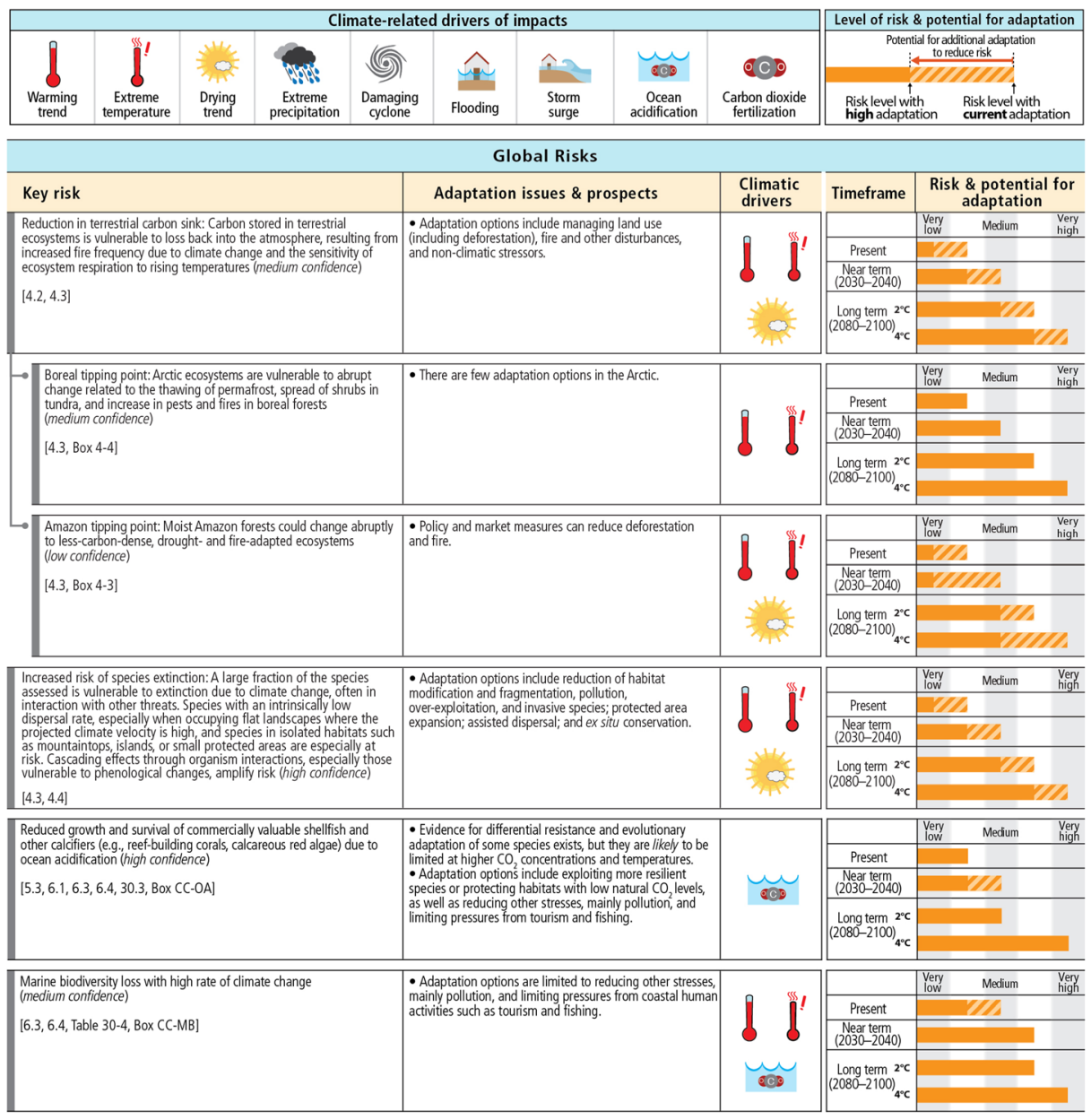

Fig. 1 Key sectoral risks presented in the WGII AR5 Technical Summary, indicating the potential for reducing risks through adaptation and mitigation. Bracketed references specify WGII AR5 sections providing a traceable account of the assessment for each key risk. Reproduced from Field et al. (2014)

expert judgment, WGII AR5 authors additionally indicate their degree of certainty in the "riskiness" of each key risk, using standardized uncertainty language adopted across the AR5 (Mastrandrea et al. 2010). Consistent with the risk framing, "high confidence" in a key risk indicates fulfillment of several key risk criteria, supported by multiple lines of robust evidence, not necessarily or solely a high probability of relevant hazards occurring.

Visual icons indicate climatic drivers of impacts for the key risks (Figs. 1 and 2), building from the Working Group I physical-science assessment and the broader WGII AR5 literature basis. The approach highlights intersections of hazards that shape risks, for example for coastal flooding, where sea level rise, extreme precipitation, and cyclones all affect risk, also with warming trends and ocean acidification reducing ecological resilience and coastal protection in some cases. These complexities of hazards, as well as their interactions with vulnerability and exposure, point to the challenges of precisely specifying where, when, and to what extent impacts will arise. 


\begin{tabular}{|c|c|c|c|c|c|c|}
\hline \multicolumn{9}{|c|}{ Climate-related drivers of impacts } \\
\hline $\begin{array}{c}\text { Warming } \\
\text { trend }\end{array}$
\end{tabular}

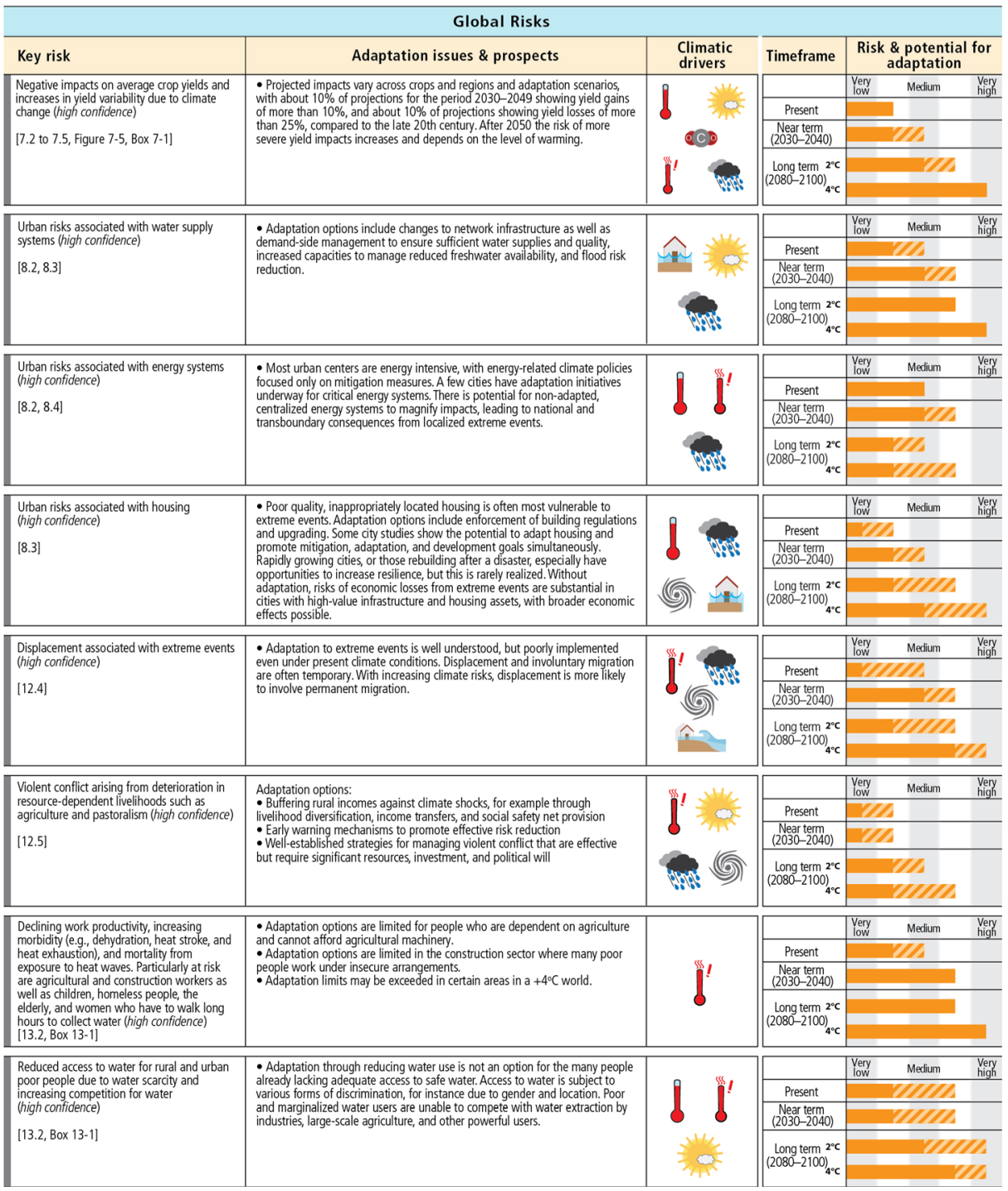

Fig. 1 (continued)

The assessment of changing risk levels is rooted in the overlapping timeframes for benefits from adaptation and mitigation. These three timeframes are broadly defined as the present, a near-term era of committed climate change, and a longer-term era of climate options. Over the next few decades (the near term), projected global temperature increase is similar across emission scenarios ranging from ambitious mitigation to continued high emissions (IPCC 2013). Even ambitious mitigation cannot prevent further climate change and associated 


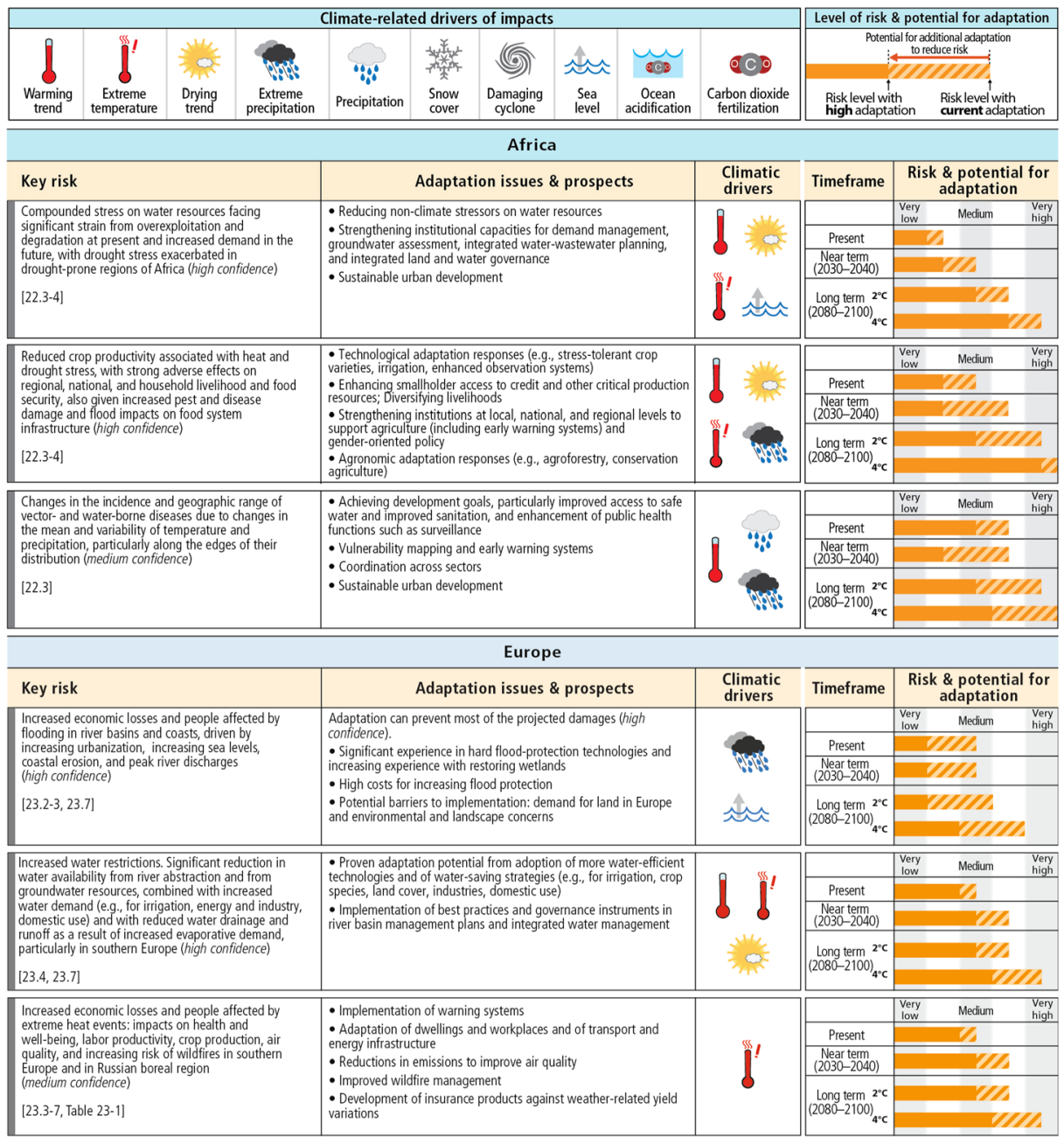

Fig. 2 Key regional risks presented in the WGII AR5 Summary for Policymakers, indicating the potential for reducing risks through adaptation and mitigation. Bracketed references specify WGII AR5 sections providing a traceable account of the assessment for each key risk. Reproduced from IPCC (2014c)

increases in risk over the next few decades, underscoring the importance of adaptations (Matthews and Solomon 2013). In the second half of the 21st century and beyond (the longer term), projected global temperature increase diverges across emission scenarios, presenting different climate options. Ambitious global mitigation, beginning today, could limit likely warming to $2{ }^{\circ} \mathrm{C}$, whereas continued high emissions would lead to substantially greater rates of warming, potentially reaching $4{ }^{\circ} \mathrm{C}$ global temperature increase above preindustrial levels within the century (IPCC 2014c). Mitigation, adaptation, and development pathways in the near term and beyond will determine climate change risks and response options in the longer term. For each key risk, WGII AR5 authors assessed risk levels for the present, the near term (specifically, 2030-2040), and the longer term for two possible futures $\left(2\right.$ and $4{ }^{\circ} \mathrm{C}$ global mean temperature increase above preindustrial levels, for 2080-2100, broadly representative of warming with ambitious mitigation versus continued high emissions). 


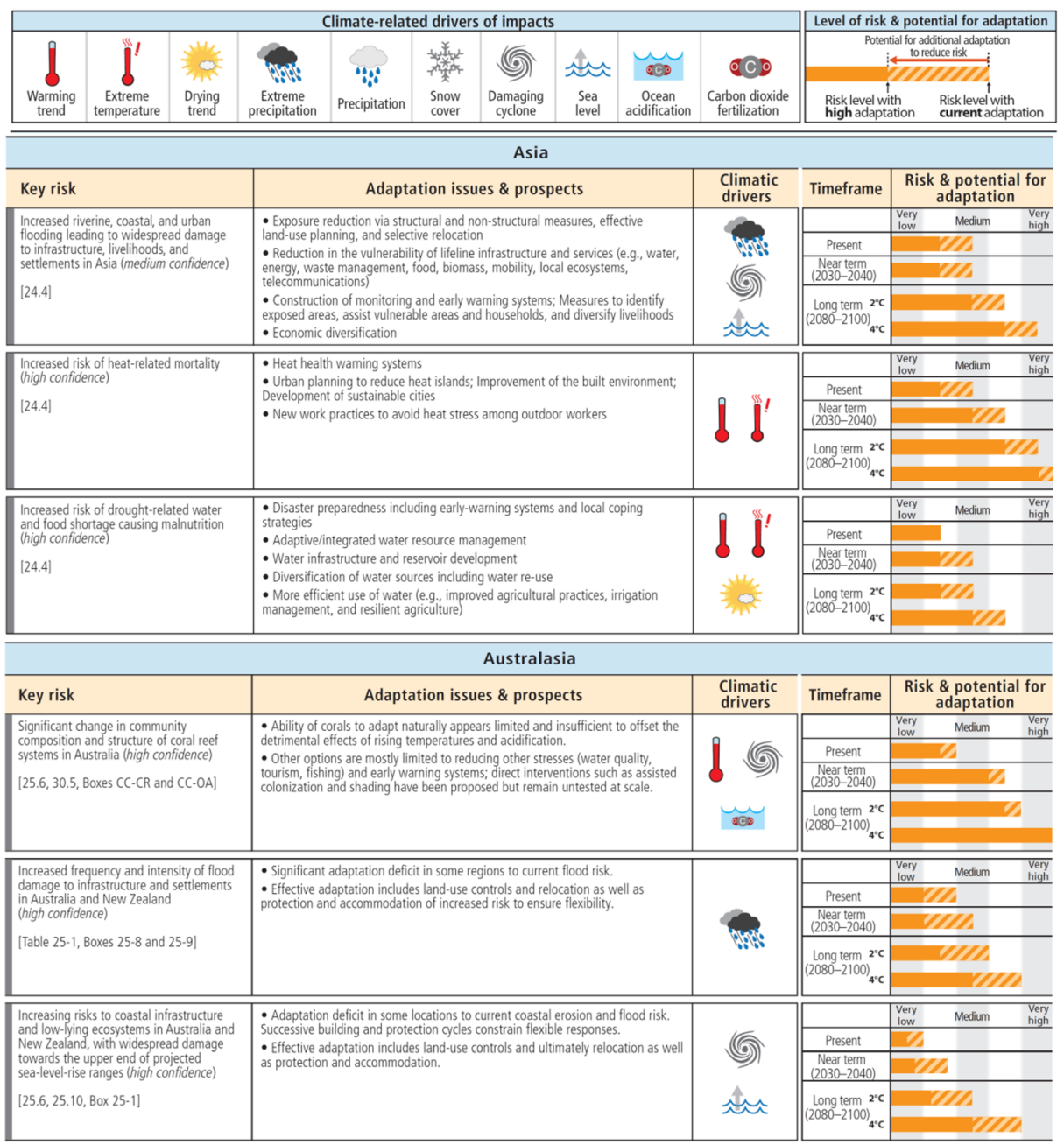

Fig. 2 (continued)

For each timeframe, risk levels were evaluated for a continuation of current adaptation and for a hypothetical status with high levels of adaptation (Figs. 1 and 2). Very low risk represents a system or process well within a margin of safety; very high risk extends perilously outside this margin. Risk reduction under high levels of adaptation could be limited by economic or societal thresholds for investments (e.g., access to financial capital, worldviews that shape risk perceptions). Or it could be expanded by response options broadened beyond those currently widespread, such as a shift from incremental to transformational adaptations (e.g., relocation of communities or economic enterprises). Risk reduction under high adaptation levels may also be bounded by physical or physiological limits to responses (e.g., mountaintops limiting species migration, human physiological limits to temperature and humidity tolerance) or a flattening of risk reduction following further adaptations (e.g., coastal vegetation restoration). 


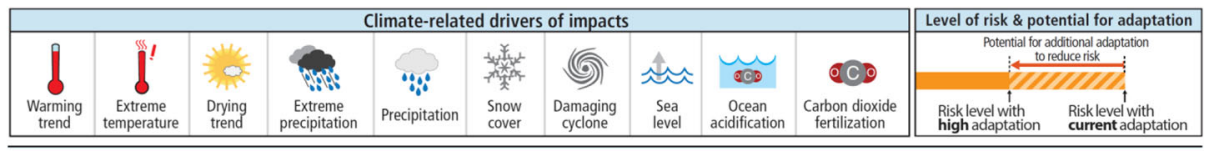

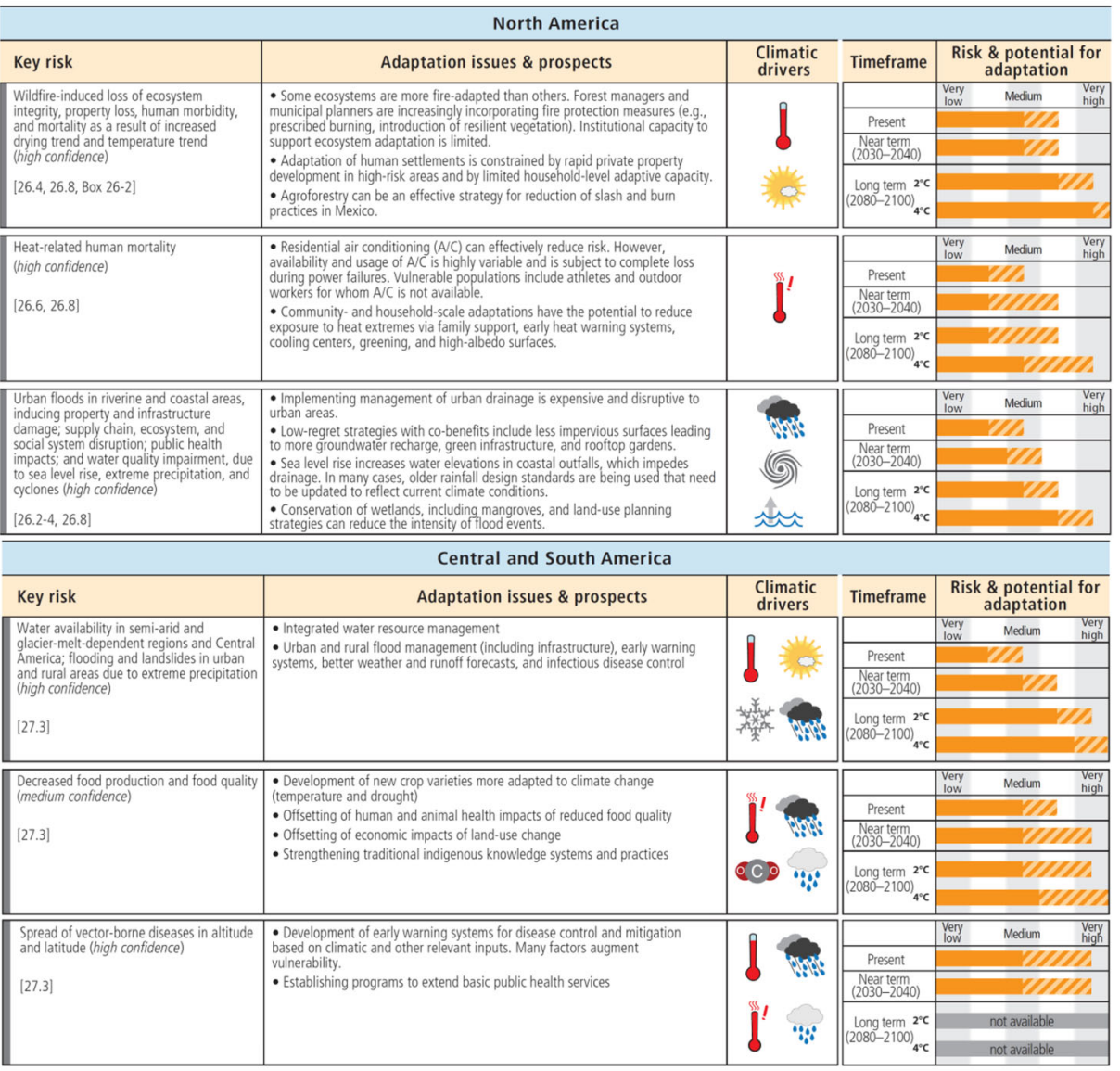

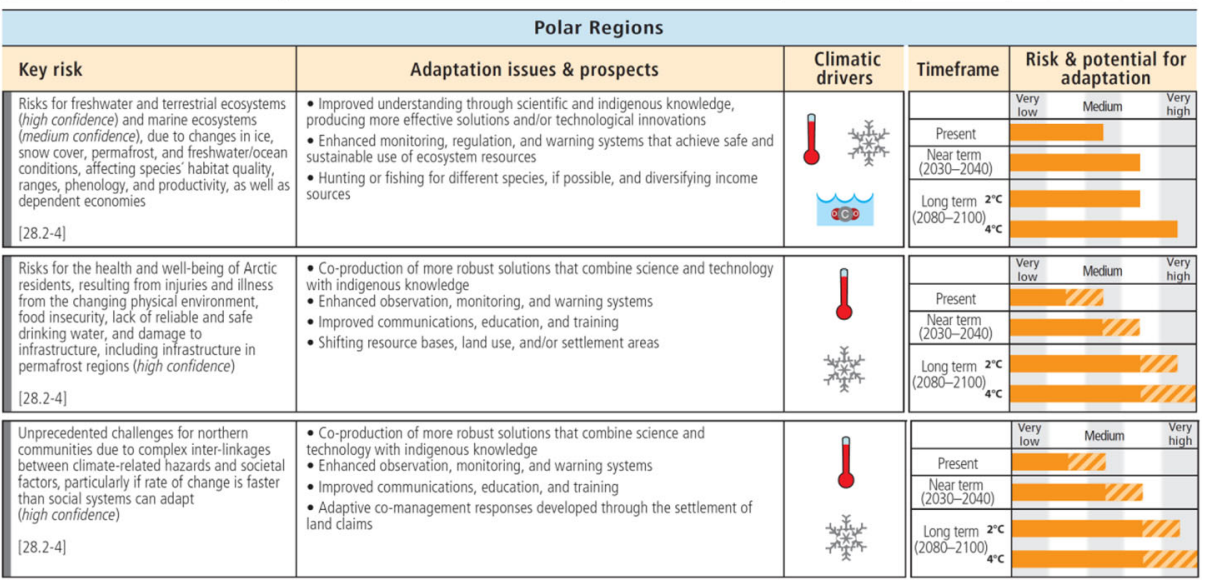

Fig. 2 (continued) 


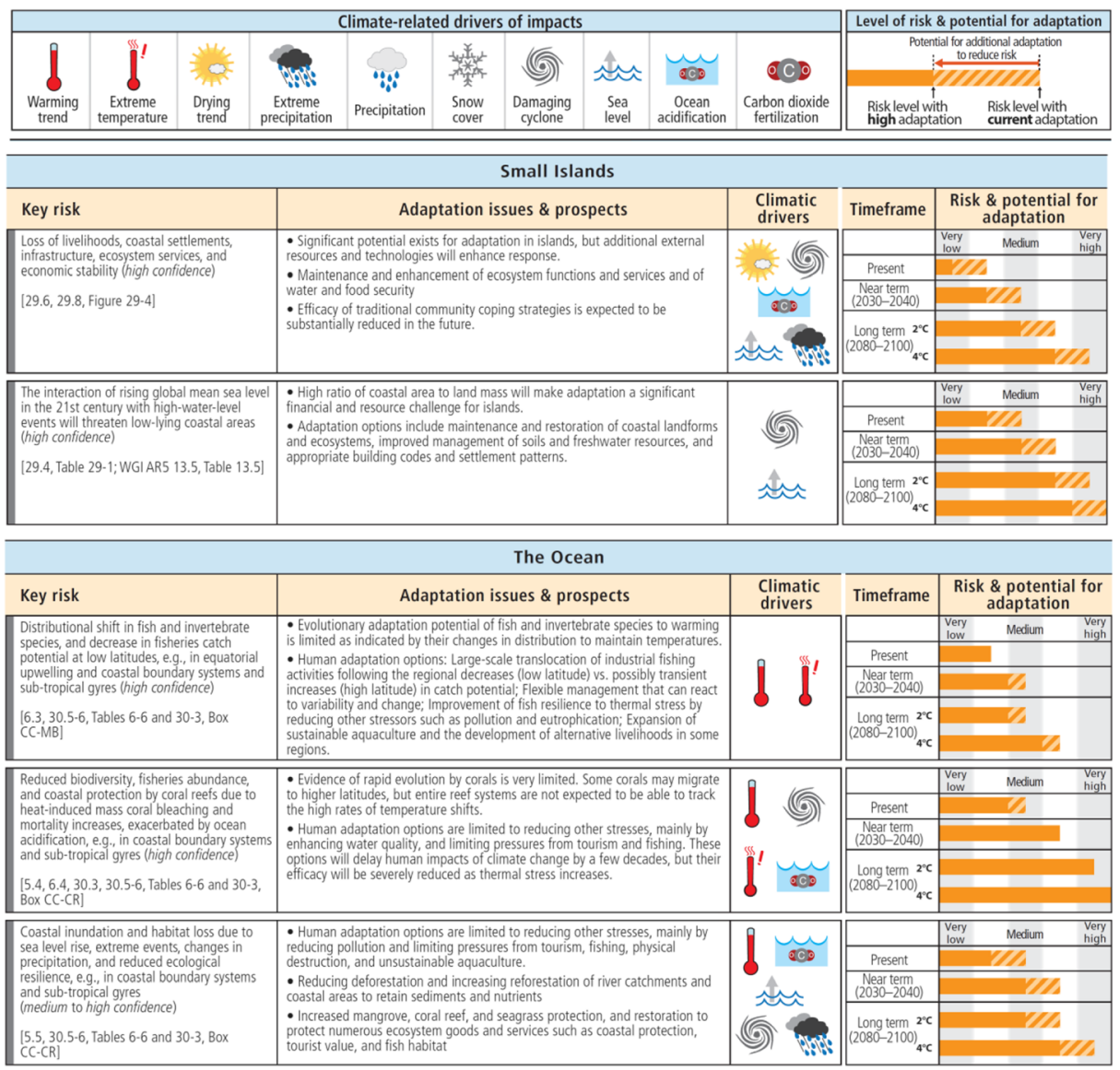

Fig. 2 (continued)

The risk levels encompass total risk due to climatic and non-climatic factors, integrating probability and consequence over a full range of possible outcomes. For example, possible consequences, with different probabilities of occurring, could range from reversible and local to severe, extensive, and potentially irreversible. When hazardous events or trends occur, consequences depend on exposure (e.g., assets in a floodplain) and vulnerability, including preparedness for possible impacts (e.g., the degree to which those assets are susceptible to or protected from harm). Building from the IPCC drafting and review process, individual WGII AR5 author teams had to make judgments about the trade-offs among probability, scale, and severity of impacts, for instance in evaluating risk levels for a high likelihood of geographically confined destruction of coral reefs, or for a high likelihood of geographically widespread, but marginal, impacts on crop yields.

The specific consequences associated with risks differ substantially. They include, for example, impacts on human health, water resources, ecosystem degradation, and infrastructure at a variety of spatial scales. Changes in risks through time will also be modulated by diverse and dynamic factors, including socioeconomic pathways, patterns of vulnerability and exposure, shifts in adaptive capacity, and risk perceptions based on values and worldviews (e.g., what people consider worth protecting). The nature of associated judgments, including 
Fig. 3 For 97 WGII AR5 key risks, frequencies of risk levels assessed for the present, for the near term (2030-2040), and for 2 and $4{ }^{\circ} \mathrm{C}$ global mean temperature increase in the long term (20802100). For each timeframe, risklevel frequencies are shown for a continuation of current adaptation (shaded bars) and for an assumption of high adaptation levels (hatched bars). Numerical ranges for each risk-level category are inclusive of the upper limits
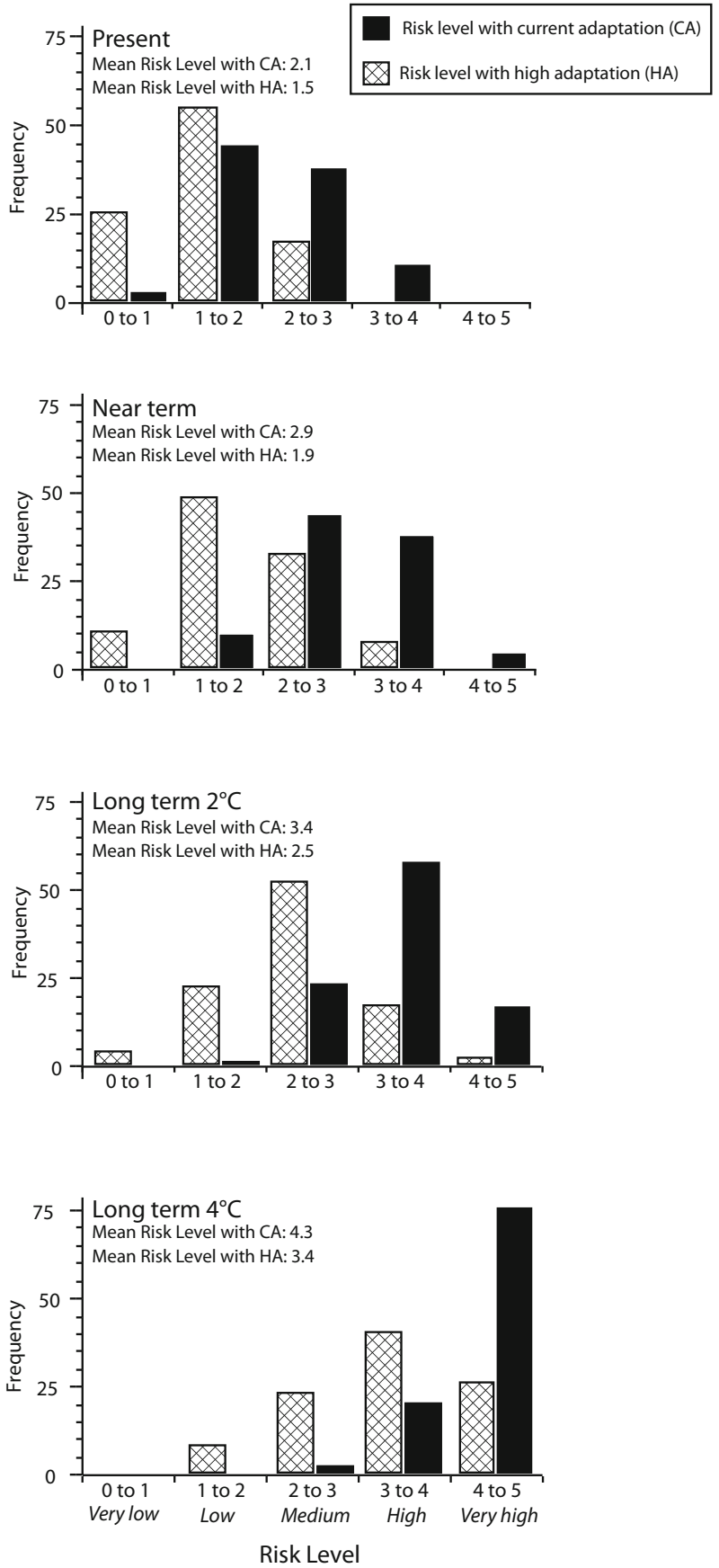

subjective views about relative probabilities of alternative development pathways, means that risk levels are not necessarily comparable across different regions and sectors. 


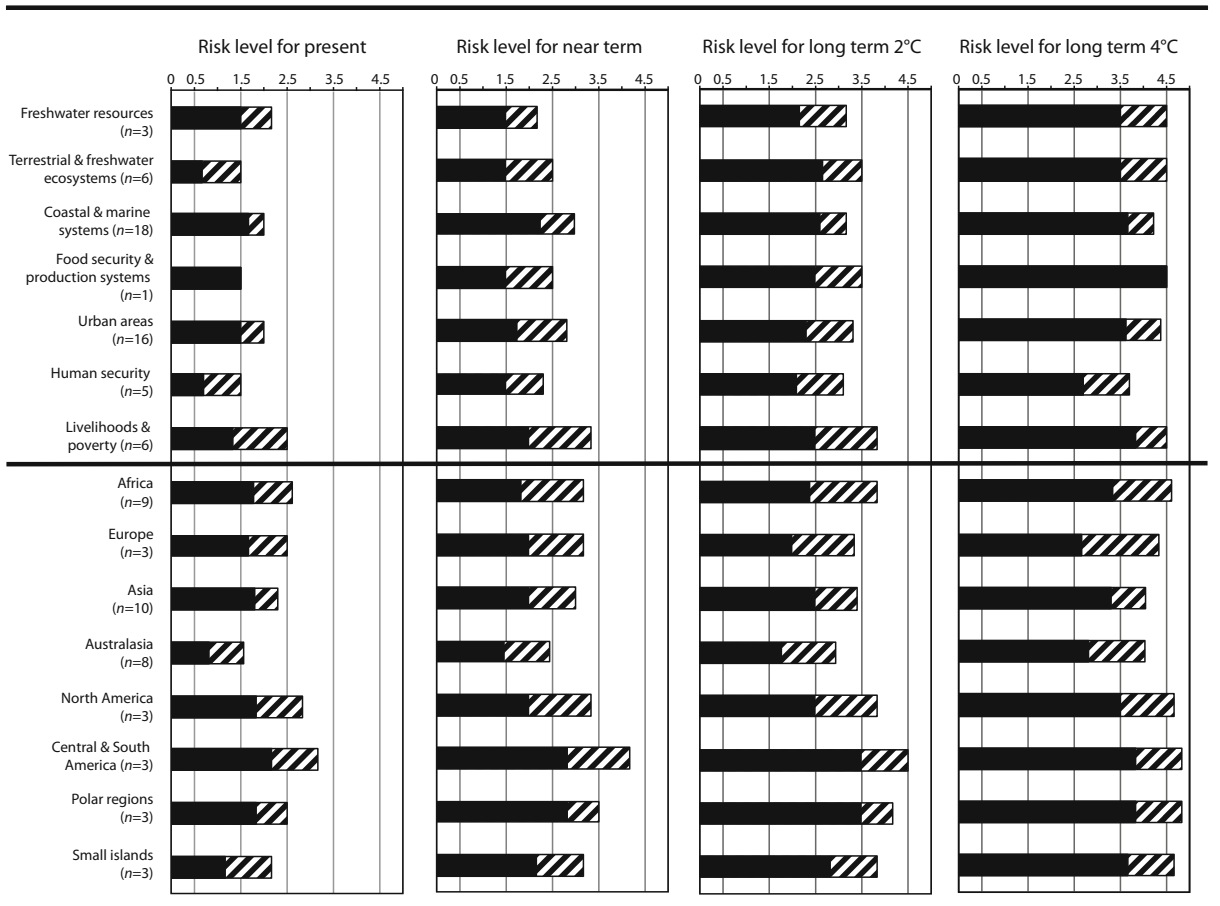

Fig. 4 For sectoral (top) and regional (bottom) key risks, assessed risk levels for the present, for the near term (2030-2040), and for 2 and $4{ }^{\circ} \mathrm{C}$ global mean temperature increase in the long term (2080-2100). For each timeframe, mean risk levels for the sector or region are indicated for a continuation of current adaptation (full extent of bar) and for an assumption of high adaptation levels (extent of black), as in Figs. 1 and 2. Regional ocean key risks are under coastal and marine systems

The visual presentation of the risk levels highlights the potential for mitigation and the potential for adaptation for each key risk (Figs. 1 and 2). For the present, the differences in risk levels for current and high adaptation indicate the potential for adaptation efforts to reduce current risks further. For the future timeframes, the risk levels show the potential for risk reduction through mitigation - the damages that could be avoided with ambitious mitigation as compared to continued high emissions. They also illustrate the assessed potential for and limits to adaptation. The key risk assessment thereby connects risks important to decision-making with mitigation and adaptation options, while acknowledging that different risks will matter most in different contexts and that science alone cannot prescribe what should be done.

\section{A shifting key risk landscape}

Here we provide a quantitative overview of risk levels assessed in the WGII AR5, integrating across expert judgments made in the key risk approach. The analysis provides a broad illustration of risk-level trends, going beyond the AR5 in evaluating overall risk-level evolutions possible through the century and the aggregate potential for risk reduction through mitigation and adaptation. Our analysis focuses on 97 of the report's key risks, excluding the numerous city-level risks unfolding the urban-areas assessment at much finer resolution 
and excluding one key risk lacking assessed risk levels for 2080-2100. We assign quantitative values to the risk levels on a scale of 0 to 5 that spans the full horizontal extent of the risk bars depicted in Figs. 1 and 2. A score of 0.5 is very low risk and 4.5 is very high risk; "1 risk unit" is the difference between consecutive risk levels (low to medium risk, high to very high risk, etc.). In this analysis, we recognize that the quantification cannot encompass all dimensions of risk and that specific interpretations of risk levels depend on personal and societal value judgments with economic, cultural, and ethical dimensions (e.g., O'Brien and Wolf 2010).

Across key risks, risk levels increase through the century (Fig. 3). Risk levels increase on average from the present to the near term (increasing from 2.1 to 2.9 with current adaptation and 1.5 to 1.9 with high adaptation). In the longer term, risk levels are greater with continued high emissions than with ambitious mitigation (mean of 4.3 versus 3.4 with current adaptation and 3.4 versus 2.5 with high adaptation). Risk-level trends for individual sectors and regions are illustrated in Fig. 4.

For key risks through the century, adaptation can contribute to risk reduction, as depicted in the hatching of the risk bars in Figs. 1, 2, and 4. Across key risks (Fig. 3), the potential for present risk reduction through adaptation is estimated as 0.6 risk units on average, indicating assessed potential for adaptation actions to decrease risk levels in our current world. Adaptation potential in the near and longer term, aggregated across all of the key risks, is assessed as larger than at present: 1.0 risk units in the near term and 0.9 risk units for both 2 and $4{ }^{\circ} \mathrm{C}$ warming in the long term. In contrast to the present, assessed adaptation potential in the near and longer term includes judgments about the range of possible socioeconomic futures and associated adaptive capacities. This adaptation-potential assessment considers the ways that more effective adaptation approaches, new technologies, or transformational responses could widen the potential for adaptation, whereas lock-in or other constraints under some development paths could decrease it, for example where infrastructural investments or outdated institutions decrease the feasibility of some adaptation options.

Across key risks in the longer term, even ambitious adaptation is insufficient to prevent risk increases resulting from climatic and non-climatic factors evolving over time (Fig. 3). Comparing present to near-term risk levels, risks increase on average by 0.8 units with a continuation of current levels of adaptation, but decrease by 0.2 units with high investments in adaptation. Jumping from present to $2{ }^{\circ} \mathrm{C}$ long-term risk levels, however, risks increase both for a continuation of current adaptation (by 1.3 risk units) and for high investments in adaptation (by 0.4 risk units), with a similar yet heightened pattern for $4{ }^{\circ} \mathrm{C}$ long-term risk levels. These risk-level patterns demonstrate limits to adaptation and point to expectations of increased impacts through the century, even with ambitious adaptation.

Mitigation reduces risk levels across the assessed key risks (Fig. 3). The difference in risks between 1.5 and $2{ }^{\circ} \mathrm{C}$ global mean temperature increase can be approximated, albeit over different timeframes, from the difference between risk levels in the near term and in the longer term for $2{ }^{\circ} \mathrm{C}$. Risk levels are greater at $2{ }^{\circ} \mathrm{C}$ as compared to $1.5{ }^{\circ} \mathrm{C}$ by 0.5 risk units on average for a continuation of current adaptation and by 0.6 risk units for high levels of adaptation. The difference between the 2 and $4{ }^{\circ} \mathrm{C}$ long-term risk levels is more pronounced: 0.9 risk units (mean) both for a continuation of current adaptation and for ambitious investments in adaptation. 
For key risks identified in the AR5, ambitious mitigation and ambitious adaptation have similar potential for risk reduction by the end of the century. While mitigation and adaptation cannot eliminate all increases in risk, the key risk assessment points to the potential for regional, sectoral, and global responses together to reduce and manage risks from climate change.

\section{Features of the climate challenge emphasized in key risks}

The WGII AR5 key risk approach highlights essential aspects of risks and responses and corresponding priorities for future research and assessment.

A complex world with complex risks The complexity of risk, embedded in a tangled matrix of interactions among multiple stressors, challenges analysis and assessment. For example, increased risk of species extinction results not just from climate change but from climate change in interaction with other stressors such as habitat modification, pollution, and invasive species, modulated by habitat geography and cascading species interactions (Fig. 1). Interconnections among risks can span sectors and regions with multiple climatic and non-climatic influences, including societal responses to climate change and other issues (Helbing 2013; Moser and Hart 2015; Oppenheimer 2013). Understanding climate change risk requires seeing this full picture. The key risk assessment enabled consideration of complex interactions, where some characteristics and processes shaping hazards, vulnerability, and exposure can be measured quantitatively and modeled probabilistically while others cannot. But adequately grappling with such interactions to inform ongoing decisions and actions will require advances beyond current scientific capabilities. Future research should more ambitiously and directly integrate qualitative understanding of complex interactions with quantitative projections exploring a subset of these interactions, which would in turn advance meaningful assessment. There are opportunities for research both to do such integration and to develop tools to enable it.

For adaptation especially, the partitioning of uncertainty across the determinants of risk matters. For some key risks, the range of possible consequences may hinge on uncertainty about future vulnerability and exposure. In other cases, the range may be driven primarily by uncertainty about the hazard trend. For instance, risks to coastal infrastructure and low-lying ecosystems can depend strongly on whether sea level rise is moderate or extreme, and to address this, the Australasia assessment separately evaluated risk levels for different sea-level-rise magnitudes. Iterative adjustment of adaptive responses over time can be a way to address such uncertainty about future sea level rise, recognizing that current choices can constrain or expand future options (e.g., Ranger et al. 2013). A priority for future assessment and research is rigorous study of adaptation effectiveness, for current and future actions, across the determinants of risk. For human as compared to natural systems, many assessed key risks imply greater potential for adaptation, but overestimating this potential or the probability of full implementation can increase the likelihood of severe consequences if adaptation falls short.

Assessment of key risks necessitates consideration of large and deep uncertainties about the human trajectory. Future wealth, technologies, governance, inequalities, 
values, and many other factors, varying through space and time, will together shape vulnerability, exposure, and response capacity. In evaluating risks, the WGII AR5 applied weightings, based on expert judgment informed by the IPCC review process, of the probabilities of different social and economic paths. WGII AR5 authors were encouraged to explore the fullest possible range of socioeconomic futures in evaluating risks. Limits to what is knowable about future vulnerability and exposure especially at the regional scale, however, likely constrained the sampling of possible futures in the risk assessment. Additionally, the assessment of the potential for and limits to adaptation can be closely linked to various assumptions about social, economic, and cultural factors that determine response capacity, risk perceptions, and implemented responses (e.g., Oppenheimer 2013). To empower decision-making through future work, research efforts must create understanding of the leverage of different choices and socioeconomic futures in transforming possible outcomes, not just treating human dimensions as homogenous and uncontested through space or time. Such research approaches can advance climate solutions and also co-benefits for other societal objectives.

A need for rigorous expert judgment Assessment requires consideration of many lines of evidence, building from observations, experiments, conceptual understanding, statistics, and models. Rigorous expert judgment is necessary in weighing the spectrum of scientific results, which draw from different methods and assumptions with associated strengths and limitations. For example, historical observations may provide insights on existing sensitivities and responses to weather and climate deviations while introducing questions about their extrapolation across possible climatic and socioeconomic futures (e.g., Hsiang et al. 2013). Case studies of impacts and adaptive responses may shed light on dynamics and cultural values essential in place-based systems that are nonetheless difficult to encompass in quantitative regional-to-global-scale impact models (e.g., Moser and Hart 2015). As a third example, results dependent on technology assumptions may reflect optimism or pessimism about technology development, diffusion, and costs, even though the role of worldview can be hard to quantify (e.g., Rosen and Guenther 2015). As part of the key risk assessment, WGII AR5 authors applied expert judgment, through the IPCC drafting and review process, to make sense of such complexities. For instance, the assessment of violent conflict had to reckon with a wide and growing spectrum of research involving diverse quantitative and qualitative methods and data, with climate change only one of many stressors in most cases; building from extensive review comments, the author teams strove to provide, in their collective expert judgment, a balanced evaluation of mechanisms of impact across competing scientific explanations (Adger et al. 2014) (e.g., Fig. 1). Such expert judgments are among the hardest tasks and greatest added value in assessment (Brysse et al. 2013; Cash et al. 2003; NRC 2009; Oppenheimer et al. 2007; Watson and Gitay 2004). Based on accumulated experience, assessment is increasingly ready for more scientific approaches to expert judgment. For example, quantitative surveys of perspectives on competing explanations can make expert judgments more transparent (e.g., Gattuso et al. 2013). There are also opportunities for addressing subjective dimensions of expert opinion directly, for instance by developing alternative conclusions across explicit normative viewpoints (such as Type I error aversion versus a precautionary approach or a distributional versus aggregate emphasis). 
The constraint of five primary risk levels (very low to very high) over four cases (present, near term, and 2 and $4{ }^{\circ} \mathrm{C}$ in the longer term) may imply more linearity in progressively increasing risk levels than WGII AR5 authors intended for some key risks. That is, the magnitude of risk or the psychological interpretation or response to risk information may increase nonlinearly, despite the linear risk scale, although such relationships were not explicitly defined within the risk levels. The frequencies of assessed risk levels across the four cases additionally suggest that authors may have run out of risk levels for higher levels of temperature increase (Fig. 3). Future research could employ expert elicitation, surveys, and structured interviews to increase understanding of how quantified magnitudes of risk are intuitively interpreted as low or high levels of risk by both scientists and decision-makers, and how expressions of risk levels in turn shape actions, for example focusing on risks expressed in terms of human lives, economic costs, or biodiversity indices.

Moving from global to regional scales, scientific literature on risk dimensions necessarily grows sparser. At smaller scales, issues are addressed less comprehensively, with more limited observations, fewer models and scenarios, and constraints on available expertise. This sparser information challenges the assessment of key risks. Based on expert judgment, WGII AR5 authors could not elevate some highly relevant potential impacts as key risks identified with high or medium confidence, given insufficient available evidence, for example for regions with limited observations or modeling of impacts on biodiversity, migration, or even crop yields. In addressing such limitations, transparent, well-defined methods of expert judgment, acknowledging inevitable implicit biases and their implications, are critical for avoiding counterproductive interpretations among target audiences, even where they require perhaps uncomfortable acknowledgment that science is not a purely objective endeavor.

Values matter At the heart of the key risk approach is a simple question: what do the risk levels mean? For example, which is more important: very high risk of commercially valuable shellfish reductions, of extinction, or of heat-related human mortality (Figs. 1 and 2)? Each will be important in different risk-management contexts, with some universals (special consideration to human life and existence) and some particulars (specific values, goals, cultures, perceptions, and socioeconomic contexts). Underscoring the diversity of what is at stake in a changing climate, the key risks establish central issues for decision-makers who are evaluating anthropogenic interference with the climate system and developing policies to prevent, or minimize, dangerous climate change. Such decisions can be supported by risk assessment, here based on WGII AR5 author expert judgment of the available scientific literature, informed by the IPCC expert and government review processes. But such decisions also require value judgments that go beyond science, reflecting a range of legitimate perspectives (Adams-Schoen et al. 2015; Adger et al. 2009; Dow et al. 2013; Knutti and Rogelj 2015; O'Brien and Wolf 2010; Tschakert 2015). In the WGII AR5, the reasons for concern provide a global perspective on climate change risk to inform such judgments, while the many key risks emphasize the complement: climate change will affect most people in most places, but in differing ways with uncertainties through time, diversely reverberating through the human experience. The resulting differential risks raise challenging questions and ethical dilemmas around whose values count and how much. 
In summary, the key risk approach in the WGII AR5 represents an advance in the application and illustration of expert judgment in assessment. It also suggests future opportunities. More comprehensive definitions of risk levels, as well as adaptation potential, could increase the transparency and consistency of judgments, including value-based judgments, made by different groups of experts; developing such definitions would require innovating criteria applicable at the level of both sectors and regions, across consequences of different probabilities, scales, and severities. Expert elicitation and other formalized methods could be incorporated to evaluate possible futures across sectors and regions, for example using structured discussions or individually elicited probability distributions to enhance the process of collective expert judgment (Morgan 2014). And embedding focus testing, surveys, and interactive sessions with decision-makers throughout an assessment, going beyond existing formal review processes, would enable more experimentation with different conceptualization, visualization, and communication approaches, enabling key risks to more deeply engage various stakeholders.

\section{Integrating scenarios and risks}

The WGII AR5 key risk assessment goes beyond scenarios. It does so by providing an overarching conceptualization of the climate challenge: responding to climate change is a challenge in understanding, reducing, and managing risks across contexts and scales; while we must contend with committed climate change, we simultaneously face choices today that will be pivotal in determining the amount of climate change that occurs in the longer term. The assessment is based on many lines of evidence, including observations and scenario- and model-based results. Current experiences, downscaled climate projections, quantitative impact simulations, and energy-economy modeling analyses are part of this evidence basis, but situating these results in the entirety of our understanding of complex social-ecological systems, through methods of expert judgment, is essential. The key risk approach enables a holistic assessment of risk that transcends disciplinary bounds of analysis and embraces the full scope of relevant quantitative and qualitative evidence, but with challenges of completely sampling the range of possible futures and at the same time remaining within the bounds of published literature. The great opportunity of assessment is providing understandable high-level summaries of scientific knowledge, directly connecting with areas of action. Doing so effectively, we argue, requires creativity and nimbleness rooted in the science, most importantly communicating its deep relevance. By making climate risks and options visible, the key risk assessment can inform judgments in a changing climate and empower responses.

Acknowledgments We thank all of the WGII AR5 authors for their expertise, dedication, and insights in the key risk assessment. P. Tschakert, A. Reisinger, M. Oppenheimer, K. O'Brien, F. Moore, J. Mach, and P. Freeman provided thoughtful feedback on early manuscript drafts. P. Freeman assisted with figure production

Author attribution KJM, MDM, and CBF conceptualized the analysis and its reflections; KJM, MDM, TEB, and CBF completed the risk-level comparisons; and KJM wrote the manuscript with revisions from all authors. 
Open Access This article is distributed under the terms of the Creative Commons Attribution 4.0 International License (http://creativecommons.org/licenses/by/4.0/), which permits unrestricted use, distribution, and reproduction in any medium, provided you give appropriate credit to the original author(s) and the source, provide a link to the Creative Commons license, and indicate if changes were made.

\section{References}

Adams-Schoen SJ, Badrinarayana D, Carlarne C, Craig RK, Dernbach JC, Hirokawa KH, Klass AB, Kuh KF, Miller ST, Owley J, Roesler S, Rosenbloom J, Scott I, Takacs D (2015) A response to the IPCC Fifth Assessment. Environ Law Rep 45:10027-10048

Adger WN, Dessai S, Goulden M, Hulme M, Lorenzoni I, Nelson D, Naess L, Wolf J, Wreford A (2009) Are there social limits to adaptation to climate change? Clim Change 93:335-354

Adger WN, Pulhin JM, Barnett J, Dabelko GD, Hovelsrud GK, Levy M, Spring ÚO, Vogel CH (2014) Human security. In: Field CB, Barros VR, Dokken DJ, Mach KJ, Mastrandrea MD, Bilir TE, Chatterjee M, Ebi KL, Estrada YO, Genova RC, Girma B, Kissel ES, Levy AN, MacCracken S, Mastrandrea PR, White LL (eds) Climate change 2014: impacts, adaptation, and vulnerability. Part A: global and sectoral aspects. Contribution of Working Group II to the Fifth Assessment Report of the Intergovernmental Panel of Climate Change. Cambridge University Press, Cambridge, pp 755-791

Brysse K, Oreskes N, O’Reilly J, Oppenheimer M (2013) Climate change prediction: erring on the side of least drama? Glob Environ Chang 23:327-337

Cash DW, Clark WC, Alcock F, Dickson NM, Eckley N, Guston DH, Jäger J, Mitchell RB (2003) Knowledge systems for sustainable development. Proc Natl Acad Sci 100:8086-8091

DHS (2011) Risk management fundamentals: homeland security risk management doctrine. In: Beers R (ed) Department of Homeland Security (DHS), Washington

Dow K, Berkhout F, Preston BL, Klein RJT, Midgley G, Shaw MR (2013) Limits to adaptation. Nat Clim Chang 3:305-307

Field CB, Barros VR, Mach KJ, Mastrandrea MD, van Aalst M, Adger WN, Arent DJ, Barnett J, Betts R, Bilir TE, Birkmann J, Carmin J, Chadee DD, Challinor AJ, Chatterjee M, Cramer W, Davidson DJ, Estrada YO, Gattuso JP, Hijioka Y, Hoegh-Guldberg O, Huang HQ, Insarov GE, Jones RN, Kovats RS, Lankao PR, Larsen JN, Losada IJ, Marengo JA, McLean RF, Mearns LO, Mechler R, Morton JF, Niang I, Oki T, Olwoch JM, Opondo M, Poloczanska ES, Pörtner HO, Redsteer MH, Reisinger A, Revi A, Schmidt DN, Shaw MR, Solecki W, Stone DA, Stone JMR, Strzepek KM, Suarez AG, Tschakert P, Valentini R, Vicuña S, Villamizar A, Vincent KE, Warren R, White LL, Wilbanks TJ, Wong PP, Yohe GW (2014) Technical summary. In: Field CB, Barros VR, Dokken DJ, Mach KJ, Mastrandrea MD, Bilir TE, Chatterjee M, Ebi KL, Estrada YO, Genova RC, Girma B, Kissel ES, Levy AN, MacCracken S, Mastrandrea PR, White LL (eds) Climate change 2014: impacts, adaptation, and vulnerability. Part A: global and sectoral aspects. Contribution of Working Group II to the Fifth Assessment Report of the Intergovernmental Panel on Climate Change. Cambridge University Press, Cambridge, pp 35-94

Gattuso J-P, Mach KJ, Morgan G (2013) Ocean acidification and its impacts: an expert survey. Clim Change 117: $725-738$

Helbing D (2013) Globally networked risks and how to respond. Nature 497:51-59

Herring SC, Hoerling MP, Peterson TC, Stott PA (2014) Explaining extreme events of 2013 from a climate perspective. Bull Am Meteorol Soc 95:S1-S96

Hsiang SM, Burke M, Miguel E (2013) Quantifying the influence of climate on human conflict. Science 341

IPCC (2007) Climate change 2007: synthesis report. Contribution of Working Groups I, II and III to the Fourth Assessment Report of the Intergovernmental Panel on Climate Change. In: Core Writing Team, Pachauri RK, Reisinger A (eds) IPCC, Geneva

IPCC (2013) Summary for policymakers. In: Stocker TF, Qin D, Plattner GK, Tignor M, Allen SK, Boschung J, Nauels A, Xia Y, Bex V, Midgley PM (eds) Climate change 2013: the physical science basis. Contribution of Working Group I to the Fifth Assessment Report of the Intergovernmental Panel on Climate Change. Cambridge University Press, Cambridge, pp 3-29

IPCC (2014a) Annex II: glossary Agard J, Schipper ELF, Birkmann J, Campos M, Dubeux C, Nojiri Y, Olsson L, Osman-Elasha B, Pelling M, Prather MJ, Rivera-Ferre MG, Ruppel OC, Sallenger A, Smith KR, St Clair AL, Mach KJ, Mastrandrea MD, and Bilir TE (eds) In: Barros VR, Field CB, Dokken DJ, Mastrandrea MD, Mach KJ, Bilir TE, Chatterjee M, Ebi KL, Estrada YO, Genova RC, Girma B, Kissel ES, Levy AN, MacCracken S, Mastrandrea PR, White LL (eds) Climate change 2014: impacts, adaptation, and vulnerability. Part B: regional aspects. Contribution of Working Group II to the Fifth Assessment Report of the Intergovernmental Panel on Climate Change. Cambridge University Press, Cambridge, pp. 1757-1776 
IPCC (2014b) Annex II: glossary. Mach KJ, Planton S, von Stechow C (eds) Climate change 2014: synthesis report. Contribution of Working Groups I, II and III to the Fifth Assessment Report of the Intergovernmental Panel on Climate Change. In: Core Writing Team, Pachauri RK, Meyer LA (eds). IPCC, Geneva, Switzerland, pp. 117-130

IPCC (2014c) Summary for policymakers. In: Field CB, Barros VR, Dokken DJ, Mach KJ, Mastrandrea MD, Bilir TE, Chatterjee M, Ebi KL, Estrada YO, Genova RC, Girma B, Kissel ES, Levy AN, MacCracken S, Mastrandrea PR, White LL (eds) Climate change 2014: impacts, adaptation, and vulnerability. Part A: global and sectoral aspects. Contribution of Working Group II to the Fifth Assessment Report of the Intergovernmental Panel on Climate Change. Cambridge University Press, Cambridge, pp 1-32

Knutti R, Rogelj J (2015) The legacy of our CO2 emissions: a clash of scientific facts, politics and ethics. Clim Chang 133:361-373

Kunreuther H, Heal G, Allen M, Edenhofer O, Field CB, Yohe G (2013) Risk management and climate change. Nat Clim Chang 3:447-450

Lempert R, Popper SW, Bankes SC (2003) Shaping the next one hundred years: new methods for quantitative, long-term policy analysis. RAND Corporation, Santa Monica

Mastrandrea MD, Field CB, Stocker TF, Edenhofer O, Ebi KL, Frame DJ, Held H, Kriegler E, Mach KJ, Matschoss PR, Plattner G-K, Yohe GW, Zwiers FW (2010) Guidance note for lead authors of the IPCC Fifth Assessment Report on consistent treatment of uncertainties. Switzerland, Geneva

Matthews HD, Solomon S (2013) Irreversible does not mean unavoidable. Science 340:438-439

Morgan MG (2014) Use (and abuse) of expert elicitation in support of decision making for public policy. Proc Natl Acad Sci 111:7176-7184

Moser S, Hart JF (2015) The long arm of climate change: societal teleconnections and the future of climate change impacts studies. Clim Change 129:13-26

NRC (2009) Informing decisions in a changing climate. The National Academies Press, Washington, DC

O'Brien KL, Wolf J (2010) A values-based approach to vulnerability and adaptation to climate change. Wiley Interdiscip Rev Clim Chang 1:232-242

Oppenheimer M (2013) Climate change impacts: accounting for the human response. Clim Change 117:439-449

Oppenheimer M, O'Neill BC, Webster M, Agrawala S (2007) The limits of consensus. Science 317:1505-1506

Oppenheimer M, Campos M, Warren R, Birkmann J, Luber G, O’Neill B, Takahashi K (2014) Emergent risks and key vulnerabilities. In: Field CB, Barros VR, Dokken DJ, Mach KJ, Mastrandrea MD, Bilir TE, Chatterjee M, Ebi KL, Estrada YO, Genova RC, Girma B, Kissel ES, Levy AN, MacCracken S, Mastrandrea PR, White LL (eds) Climate change 2014: impacts, adaptation, and vulnerability. Part A: global and sectoral aspects. Contribution of Working Group II to the Fifth Assessment Report of the Intergovernmental Panel of Climate Change. Cambridge University Press, Cambridge, pp 1039-1099

Ranger N, Reeder T, Lowe J (2013) Addressing 'deep' uncertainty over long-term climate in major infrastructure projects: four innovations of the Thames Estuary 2100 Project. EURO J Decis Process 1:233-262

Rosen RA, Guenther E (2015) The economics of mitigating climate change: what can we know? Technol Forecast Soc Chang 91:93-106

Schneider SH, Semenov S, Patwardhan A, Burton I, Magadza CHD, Oppenheimer M, Pittock AB, Rahman A, Smith JB, Suarez A, Yamin F (2007) Assessing key vulnerabilities and the risk from climate change. In: Parry ML, Canziani OF, Palutikof JP, van der Linden PJ, Hanson CE (eds) Climate change 2007: impacts, adaptation and vulnerability. Contribution of Working Group II to the Fourth Assessment Report of the Intergovernmental Panel on Climate Change. Cambridge University Press, Cambridge, pp 779-810

Smith JB, Schellnhuber HJ, Mirza MMQ, Fankhauser S, Leemans R, Erda L, Ogallo L, Pittock B, Richels R, Rosenzweig C, Safriel U, Tol RSJ, Weyant J, Yohe G (2001) Vulnerability to climate change and reasons for concern: a synthesis. In: McCarthy JJ, Canziani OF, Leary NA, Dokken DJ, White KS (eds) Climate change 2001: impacts, adaptation and vulnerability. Contribution of Working Group II to the Third Assessment Report of the Intergovernmental Panel on Climate Change. Cambridge University Press, Cambridge, pp 913-967

Smith JB, Schneider SH, Oppenheimer M, Yohe GW, Hare W, Mastrandrea MD, Patwardhan A, Burton I, Corfee-Morlot J, Magadza CHD, Füssel H-M, Pittock AB, Rahman A, Suarez A, van Ypersele J-P (2009) Assessing dangerous climate change through an update of the Intergovernmental Panel on Climate Change (IPCC) "reasons for concern". Proc Natl Acad Sci 106:4133-4137

Tschakert $\mathrm{P}(2015) 1.5^{\circ} \mathrm{C}$ or $2^{\circ} \mathrm{C}$ : a conduit's view from the science policy interface at COP20 in Lima, Peru. Climate Change Responses 2

Watson RT, Gitay H (2004) Mobilization, diffusion and use of scientific expertise. IDDRI (Institut du Développement Durable et des Relations Internationales), Paris 